\title{
GLOBALIZAÇÃO, CONTRARREVOLUÇÃO E NOVA SENSIBILIDADE: LEITURA DAS PALESTRAS DE PARIS DE 1974 DE MARCUSE
}

\author{
GLOBALIZACIÓN, CONTRARREVOLUCIÓN Y NUEVA \\ SENSIBILIDADE: LECTURA DE LAS CONFERENCIAS DE PARÍS \\ DE 1974 DE MARCUSE
}

\section{GLOBALIZATION, COUNTERREVOLUTION AND NEW SENSIBILITY: READING MARCUSE'S 1974 PARIS LECTURES}

Robespierre de OLIVEIRA ${ }^{\mathrm{I}}$

\begin{abstract}
Resumo O artigo visa apresentar e destacar aspectos essenciais das palestras que Marcuse fez em Paris, em 1974. Essas palestras contribuem para o entendimento da preocupação de Marcuse com o processo de contrarrevolução e mostram sua antecipação sobre determinados fenômenos que estavam em seu início: a terceirização, a globalização, o neoliberalismo. Marcuse já havia elaborado sua perspectiva crítica ao desenvolvimento do capitalismo tardio em $O$ homem unidimensional (1964). E continua a utilizar seu instrumental crítico em sua análise dez anos depois.

Palavras-chave: Teoria crítica; Marcuse; Sociedade unidimensional; Globalização; Contrarrevoluç̧̃̃o; Nova Sensibilidade.
\end{abstract}

Abstract The paper aims to show and highlight essential aspects of Marcuse's Paris Lectures in 1974. These lectures contribute to understand Marcuse's concern with the counterrevolution process. They show his anticipation about certain phenomena that were at their beginning: outsourcing, globalization, and neoliberalism. Marcuse had elaborated his critical perspective towards late capitalism in One-dimensional Man (1964). Moreover, he continues to use his critical tools in these lectures ten years later.

Key-words: Critical Theory; Marcuse; One-dimensional Society; Globalization; CounterReVolution; New Sensibility.

${ }^{1}$ Universidade Estadual de Maringá (UEM), Maringá/PR - Brasil. 
Resumen El artículo pretende presentar y destacar aspectos esenciales de las conferencias que Marcuse hizo en París en 1974. Estas conferencias contribuyen al entendimiento de la preocupación de Marcuse con el proceso de contrarrevolución y muestran su anticipación sobre determinados fenómenos que estaban en su inicio: la tercerización, la globalización, el neoliberalismo. Marcuse ya había elaborado su perspectiva crítica al desarrollo del capitalismo tardío en El hombre unidimensional (1964). Y continúa utilizando su instrumental crítico en su análisis diez años después.

Palabras clave: Teoría crítica; Marcuse; Sociedad unidimensional; Globalización; Contrarrevolución; Nueva sensibilidade.

Em 1974, Herbert Marcuse deu palestras na Universidade de Paris VIII, em Vincenes. Foram cerca de sete palestras, reunidas em um volume publicado recentemente por Charles Reitz e Peter-Erwin Jansen (2015). Nessas palestras, ele discorre a respeito do processo de contrarrevolução, o neoliberalismo, e o processo de globalização do capitalismo. Segundo Sarah Surak, que faz introdução ao livro publicado das palestras, Marcuse, em resposta aos dez anos da publicação de $O$ homem unidimensional (1964), discorreu sobre "as causas e consequências das forças estabilizados do monopólio do capitalismo americano, tanto quanto das possibilidades para a radical transformação econômica e das relações sociais. As palestras, enquanto fundadas em sua crítica inicial da sociedade industrial avançada americana, refletem o tom cada vez mais militante encontrado em seus escritos posteriores" (SURAK. In: JANSEN; REITZ, 2015, p. ix). ${ }^{1}$

Marcuse inicia suas palestras reconhecendo o poderio dos EUA como o maior país do mundo, econômica, tecnológica e militarmente, sendo a mais avançada forma do capitalismo de monopólio. De fato, os EUA ascenderam à potência mundial após a Segunda Guerra Mundial, continuando sua ofensiva militar durante a Guerra Fria. Isto significou intervenções militares, incluindo tentativas de ocupações territoriais, expandindo seu mercado. Nesse processo, os EUA buscaram investir em golpes de Estado e nas tentativas frustradas de derrotar a Revolução Cubana após Fidel Castro aproximar-se do comunismo. O Golpe de Estado no Brasil, em 1964, fez parte desse processo de contrarrevolução, resultando inclusive na proliferação da cultura norte-americana contra a cultura nacional. As guerras da Coreia e do Vietnã, a partir dos anos 1950, também fizeram parte disso. A última provocou um forte processo de resistência dos cidadãos norte-americanos levando à derrota do país nessa guerra. Ao mesmo tempo, o desenvolvimento tecnológico, após a Segunda Guerra, fortaleceu a arrancada econômica do país e mudou o modo de vida dos norte-americanos. Houve o surgimento do movimento dos negros pelos direitos civis, o movimento feminista cresceu, o movimento ecológico havia começado a se colocar, a revolução sexual possibilitou uma nova relação entre os jovens. Houve também reações a isso, como os assassi-

\footnotetext{
1 "Responding to the tenth anniversary of the publication of One-Dimensional Man, Marcuse addressed the causes and consequences of the stabilizing forces of American monopoly capitalism as well as possibilities for radical transformation of economic and social relations. The lectures, while grounded in his initial critique of American advanced industrial society, reflect the increasingly militant tone found in his subsequent writings" [tradução do autor].
} 
natos de Malcolm X e Martin Luther King Jr., repressões aos estudantes. A possibilidade de libertação nos anos 1960 foram atacadas com a invasão soviética em Praga, em 1968, o recrudescimento das ditaduras na América Latina, o golpe de Estado no Chile, entre outros exemplos. A crise do petróleo nos anos 1970 levou à política do neoliberalismo, capitaneada por Margaret Thatcher, que se pôs contra o Estado de bem-estar social. É nesse horizonte que ocorreram as palestras de Marcuse.

As contradições da sociedade norte-americana foram elaboradas em $O$ homem unidimensional. A sociedade unidimensional é uma sociedade que fornece uma falsa sensação de liberdade, mediante um processo de integração e contenção. Os indivíduos são mobilizados, por meio do consumo, a se integrarem à ordem estabelecida. $\mathrm{O}$ acesso democrático à cultura e ao consumo de produtos, principalmente tecnológicos, promove essa falsa percepção de liberdade. As facilidades fornecidas pelos aparelhos tecnológicos produzem uma sensação de maior controle dos indivíduos. Entretanto, os indivíduos são manipulados por esses mesmos meios. Assim, colocando em termos atuais, o uso de redes sociais parece inserir os indivíduos em uma comunidade maior, quando pode levar ao isolamento mesmo desses indivíduos. Marcuse criticava a racionalidade tecnológica e a obsessão pelo aperfeiçoamento tecnológico, o qual leva a uma exaustão dos recursos. Em suas palestras, ele aponta que a sociedade industrial avançada tornou-se produtora de desperdício e forças destrutivas. Trata-se de uma alusão, por um lado, à grande produção de lixo (poderíamos incluir o lixo eletrônico) e, por outro, à produção de armamentos. Segundo seu texto, “A1gumas implicações sociais da tecnologia moderna" (1941), a tecnologia não é neutra, pois sua intencionalidade já é determinada em sua produção. Desse modo, a tecnologia insere os indivíduos numa roda-viva de trabalho e consumo, atando-os ao sistema de dominação.

O processo de contenção é estabelecido, principalmente, pela mídia e indústria cultural. Nesse processo, faz parte a educação e a elaboração da linguagem orwelliana que inverte os significados ("guerra é paz", "liberdade é escravidão", "ignorância é força”). Os políticos à frente do Estado, a mídia, a indústria cultural, defendem seus propósitos autoritários, sexistas, racistas, homofóbicos etc., mediante um discurso que, aparentemente, seria o oposto. Defendem a democracia, quando querem maior controle sobre o Estado, defendem a liberdade de religião, quando querem impor sua própria visão religiosa. Pelo menos desde "Industrialização e capitalismo na obra de Max Weber" (1964), Marcuse reconhece o papel autoritário da democracia burguesa. Nesse texto, há a menção de Weber para o desenvolvimento de uma "democracia plebiscitária", na qual os cidadãos são chamados a votar apenas para decidir sobre o que foi previamente estabelecido. Marcuse, ao longo de sua experiência nos EUA, critica o caráter autoritário da democracia norte-americana, que é fundada na exigência de campanhas milionárias. Eu cito:

O capitalismo dos EUA ainda retém este poder estabilizador numa forma reorganizada, reorganizada em escala nacional tanto quanto global. Alguns indicadores desta reorganização: Em escala nacional, nos recentes anos testemunhamos uma considerável e crescente restrição aos direitos e liberdades civis pela justiça (courts), por decreto administrativo, pela legislação. Observamos uma continuada e crescente manipulação do ainda existente processo democrático, como se não houvesse bastante manipulação antes. Se é impossível ser um can- 
didato nas eleições sem dispor de uma fortuna de cerca de um milhão de dólares, isto é em qualquer caso uma estranha forma de democracia (MARCUSE. In: JANSEN; REITZ, 2015, p. 5). ${ }^{2}$

Dada essa configuração econômica, apenas dois partidos na prática conseguem condições para bancar as eleições nacionais. Os demais partidos necessitam negociar o apoio a esses dois grandes partidos a fim de terem alguma expressão local. Não se pode afirmar que essa configuração seja responsável pela abstenção ao voto, mas, como o voto não é obrigatório, a abstenção tem crescido nos EUA. Essa configuração também causa a ingerência de grupos econômicos, empresários dos mais diversos setores (armas, petróleo, comunicação, alimentos etc.) no processo eleitoral para garantir seus representantes na estrutura de poder. Não se trata de uma situação específica dos EUA, a corrupção é inerente ao Estado capitalista. Mas tal ingerência no Estado de grupos econômicos em detrimento do interesse social levou a uma situação nova: a clara utilização do Estado para benefícios próprios desses grupos (não se pode considerá-los como um todo, muitos disputam entre si), exigindo maior exploração, flexibilidade de leis. Seguindo Max Horkheimer, que elaborou a teoria dos Rackets, Marcuse afirma que a estrutura do Estado capitalista foi tomada por uma máfia: ${ }^{3}$

Ao mesmo tempo, acredito que podemos observar nos Estados Unidos um fenômeno de grande importância que gostaria de chamar de decomposição, desintegração mesmo, da burguesia como classe dominante. É claro que a burguesia ainda é a classe dominante, mas como tal sofreu mudanças significativas. A diferença entre negócio legítimo e ilegítimo está constantemente sendo ofuscada, e o poder econômico e político da assim chamada Máfia se estende para todos os ramos da vida política e econômica (MARCUSE. In: JANSEN; REITZ, 2015, p. 2). ${ }^{4}$

Mais ainda: Marcuse afirma que essa reorganização em escala nacional é expandida em escala global (MARCUSE. In: JANSEN; REITZ, 2015, p. 6, 7). ${ }^{5}$ De fato, Marcuse está

2 "U.S. capitalism still retains a considerable degree of stabilizing power. Capitalism retains this stabilizing power in a reorganized form, reorganized on the national as well as global scale. A few indications of this reorganization: On the national scale, in the recent years we have witnessed a considerable and still growing restriction on civil rights and liberties by the courts, by administrative decree, by legislation. We have observed a continued and a growing manipulation of the still-existing democratic process, as if it would not have been manipulated enough already before. If it is impossible to become a candidate in the elections without disposing of a fortune of around a million dollars, this is in any case a strange form of democracy."

3 É curioso observar que $\mathrm{Al}$ Capone aplicou o sistema de corporação capitalista às suas atividades criminosas, como se fossem empresas, e agora as corporações capitalistas agem de acordo com as atividades criminosas.

4 "At the same time I think we can observe in the United States a phenomenon of great importance which I would like to call the decomposition, even disintegration, of the bourgeoisie as a dominant class. Of course, the bourgeoisie still is the dominant class, but as such it has undergone significant changes. The difference between legitimate and illegitimate business is constantly being obfuscated, and the economic and political power of the so-called Mafia extends itself to all branches of economic and political life."

5 "The reorganization on the national scale is accompanied by a reorganization on a global scale, mainly through the new forms of imperialism and of colonialism, so-called indirect colonialism, which in many cases seems to be even more profitable that the direct previous forms of colonialism, which, at least in Latin America, have long since been replaced by — or, rather, taken over by - the indigenous ruling classes and the indigenous armies which do the job for metropolitan capitalist countries." 
vislumbrando o início do processo de globalização que tomou fôlego no final dos anos 1980, principalmente com o fim da União Soviética e dos países do bloco "comunista" europeu. Entre as características apontadas por Marcuse estão a pós-industrialização, ${ }^{6}$ a terceirização do trabalho e o colonialismo indireto. A pós-industrialização implica a produção industrial em outros países, em que os países de origem detêm as patentes de produção. Assim, a terceirização e o colonialismo indireto funcionam para o provimento de mão de obra barata, leis trabalhistas flexíveis, além de matéria-prima mais barata. Isso possibilitou, por exemplo, empresas norte-americanas construírem fábricas no leste asiático para produzirem suas mercadorias a baixo custo, principalmente por esses outros países não seguirem as leis norte-americanas, sendo possível mercadorias de empresas norte-americanas serem fabricadas por intermédio de trabalho escravo ou infantil. Os Estados Unidos, assim, tornaram-se uma sociedade pós-industrial, na medida em que boa parte da produção industrial foi transferida para outros países, ${ }^{7}$ crescendo internamente o setor de serviços.

Segundo Marcuse:

O conceito ideológico de uma sociedade pós-industrial serve bem para mascarar e para esconder a verdadeira estrutura de poder que domina no presente estágio do capitalismo. A sociedade pós-industrial como conceito serve bem este propósito de esconder ao substituir a intenção técnica e funcional para a classe dominante verdadeira. Seria nonsense negar o constante crescimento, quantitativa e qualitativamente, dos assim chamados trabalhadores de conhecimento e o papel do conhecimento mais do que o trabalho manual no processo produtivo como um todo" (MARCUSE. In: JANSEN; REITZ, 2015, p. 14, 15). ${ }^{8}$

Marcuse observa, então, três pontos críticos. O primeiro aponta que os "trabalhadores de conhecimento" não seriam propriamente intelectuais no sentido mais tradicional, e sob essa categoria são subsumidos diversos estratos e indivíduos que pertencem à classe trabalhadora. Isto é, o fato de serem gerentes, analistas, designers, significa apenas serem trabalhadores treinados para tal. O segundo aponta que a aplicação de conhecimento ao processo de produção ainda é dependente da classe dominante, o que seria um fator limitante na produção de conhecimento. Esse conhecimento é circunscrito à racionalidade tecnológica, sendo ideológico. O terceiro ponto critica a própria noção de conhecimento. Que conhecimento? Pergunta Marcuse. Isto é, para ele, o conceito de sociedade pós-industrial é um conceito altamente ideológico na medida em que reflete um desdobramento da própria sociedade capitalista e a expansão de sua dominação e não uma sociedade melhor, emancipada.

6 Conceito ancorado em John K. Galbraith e Daniel Bell, que escreveu The Coming of Post-Industrial Society.

7 Pode-se observar que apenas setores chave, como a indústria bélica, permaneceriam nos EUA.

8 "The ideological concept of a postindustrial society serves well to mask and to conceal the actual power structure which rules at the present stage of capitalism. Post-industrial society as a concept serves well this concealing purpose by substituting the technical and functional intention for the actually ruling class. It would be nonsense to deny the constant growth, quantitatively and qualitatively, of the so-called knowledge workers and the role of knowledge rather than manual labor in the productive process as a whole." 
Segundo Marx, as crises econômicas do sistema capitalista são estruturais, consequência do crescimento mesmo da economia, que é seguido pela recessão. São as chamadas ondas de crise, às vezes mais longas, às vezes menos; com períodos de tranquilidade mais largos ou não. A ascensão econômica estourou no fim dos anos 1960, com a crise do petróleo. Houve breve recuperação nos anos 1990 e retornou à crise no século XXI. Desse modo, a reorganização do capital é necessária para repor o lucro perdido nos processos de crise. Os capitalistas não têm escrúpulos no modo como procedem a tal reorganização, mesmo que tenham que detonar guerras, ataques internos aos trabalhadores, submissão ao imperialismo, realocação de força de trabalho em outros territórios, nos quais a legislação permite maior exploração, mão de obra mais barata etc.

O desenvolvimento da tecnologia aumentou imensamente a capacidade de produção de mercadorias. Sociedades desiguais e repressivas também se reproduzem por meio da produção e negociação de dispositivos comerciais como tablets e smartphones, produção da qual também aumenta a exploração de mais-valia. Emmanuel Saez e Thomas Piketty documentaram que nos EUA de hoje cerca de metade dos ganhos que a economia produz é canalizado para os $10 \%$ mais ricos. ${ }^{9} \mathrm{Na}$ maioria do mundo, as condições da classe trabalhadora são muito piores e a parte da força de trabalho da renda nacional é cada vez mais desigual. Enquanto nos EUA as pessoas são grandes consumidoras de produtos da Apple, esses produtos são fabricados sob condições atrozes na China. ${ }^{10}$

A queda do muro de Berlim, 1989, e o fim da União Soviética, 1991, que fizeram parte do processo de globalização, teriam sido antecipados por Marcuse quando ele critica os países "comunistas" por competirem com o capitalismo nos termos deste. Na medida em que a verdade da teoria marxista não foi realizada pela União Soviética e demais países, o fim da configuração desses países não significou o fracasso da teoria marxista, mas tão-somente de sua prática política. Marcuse havia criticado o marxismo Soviético em seu livro de 1958, no qual assume como certa a doutrina do Estado soviético para mostrar suas contradições internas e com a própria teoria marxista. Assim, o propalado "fracasso da teoria marxista" seria apenas propaganda ideológica da mídia capitalista, que também proclamou "o fim das ideologias" em 1989. Na verdade, isso não foi novidade, em O homem unidimensional (1964), Marcuse criticara Daniel Bell por proclamar “o fim das ideologias”. Nem houve o "fim da história", nem desapareceram as ideologias, houve uma nova reacomodação: a chamada Nova Ordem Mundial. Assim, embora não vivesse para ver tal desenvolvimento, Marcuse elaborou sobre as tendências existentes vislumbrando o que viria a ser.

O processo de integração, que enfraqueceu a oposição no final dos anos 1960 e contribuiu para a contenção, foi descrito por Marcuse com a palavra Gleichschaltung, que era utilizada pelo Estado nazista para imprimir um pensamento único.

Os vários componentes de doutrinação, manipulação, e gerenciamento da mente, também se tornam —e este é o ponto interessante-também se tornam ins-

9 Cf. Lowery (2013). Para uma discussão detalhada, ver Reitz; Spartan, 2015, p. 19-41.

10 Veja o caso dos suicídios na Foxconn na China, em 2010, devido às condições de trabalho. 
trumentos para expressar a vontade e os interesses da população doutrinada. Há, para usar uma palavra terrível, claramente Gleichschaltung. O governo e suas instituições, a classe dominante sistematicamente produz o que é chamado de opinião pública, mas uma vez produzida, esta opinião, que é constantemente reafirmada, tem por sua vez sua própria influência sobre os legisladores [policy makers] (MARCUSE. In: JANSEN e REITZ, 2015, p. 28). ${ }^{11}$

Segundo Reitz (2016), a política nazista da Gleichschaltung estaria na base da elaboração do conceito da sociedade unidimensional de Marcuse. Essa prática significava que toda a opinião pública deveria convergir numa só direção, no caso da Alemanha, em favor da visão do Führer. O uso da propaganda por Goebbels faz parte dessa prática; a criação do inimigo comum, a sensação de insegurança que só poderia ser resolvida pelo Estado forte, a utilização de dados negativos da economia, como o desemprego e baixos salários, atribuindo-os aos inimigos internos e externos (retirando do governo sua responsabilidade) são alguns dos elementos dessa prática. Essa manipulação dos sentimentos, como o medo, reforça preconceitos, racismo, sexismo, xenofobia, homofobia. A estrutura democrática do Estado torna-se mais autoritária, servindo a agentes do poder econômico, por meio de líderes populistas, com o apoio da mídia. Se Hitler ainda poderia ser pensado como uma figura "paterna", na fase do capitalismo tardio, os líderes seriam, de acordo com Marcuse, mais como um irmão, o "Grande Irmão". Aparecem cada vez mais como caricaturas, sem condições de serem entes morais. A crise energética, mencionada por Marcuse, que levaria a uma maior dependência de países como EUA e Japão de países produtores de petróleo, pode manipular a opinião pública consumidora de gasolina para uma maior pressão sobre os países produtores de petróleo, e eventualmente guerras contra eles.

Certamente, a população subjacente fica à mercê dos poderes estabelecidos, sendo mais oprimida por seu medo pela sobrevivência. Mesmo as classes ascendentes, a classe média, não seriam, segundo Marcuse, propriamente uma nova classe, mas parte da classe trabalhadora. Com a pós-industrialização e a globalização, elas se tornam cada vez mais dependentes e, ao mesmo tempo, vulneráveis ao processo econômico. Do mesmo modo que consomem produtos além da necessidade básica (falsas necessidades, para Marcuse), também consomem produtos cada vez mais submetidos à lógica da obsolescência, produtos com qualidade cada vez menor. O desenvolvimento disso levaria a uma implosão do sistema com o aumento da produção de mercadorias, envolvendo a diminuição de recursos naturais e energia, e o aumento da pobreza inclusive nos países industriais avançados. De acordo com Marcuse, "este enorme sistema com uma população dependente de cerca de $90 \%$ reproduz, com toda sua riqueza, pobreza e desemprego numa escala sem precedente" (MARCUSE. In: JANSEN; REITZ, 2015, p. 42).

11 "The various components of indoctrination, manipulation, and management of the mind also become - and this is the interesting point-also become instruments for expressing the will and the interests of the indoctrinated population. There is, to use a horrible word, clearly Gleichschaltung. The government and its institutions, the ruling class, systematically makes what is called public opinion, but once made, this public opinion, which is constantly being reasserted, has in turn its own influence on the policy makers." 
Não só a concentração de renda, mas o processo de exclusão de parcelas consideráveis da população de direitos e acesso às facilidades do sistema, aumentam as contradições inerentes à sociedade capitalista. Marcuse cita Marx e sua análise do capitalismo para corroborar e elaborar sua própria análise. Mantendo-se próximo da perspectiva de Rosa Luxemburg, para quem a espontaneidade de luta dos trabalhadores é um primeiro passo para a organização revolucionária, Marcuse observa, assim, a possibilidade de novos movimentos de protesto anticapitalistas. Os movimentos dos anos 1960 foram integrados ou enfraquecidos nos anos 1970, mas deixaram suas sementes. Isto, principalmente, porque as questões desses movimentos não foram resolvidas e seus problemas só tenderiam a aumentar em termos de exclusão. Segundo Marcuse:

\begin{abstract}
“(...) Esta contradição ameaça explodir; não espalhando pobreza e miséria nas metrópoles, mas ao contrário, pela conquista potencial da carência material e miséria. Isto é, a contradição se desenvolve num nível relativamente alto de vida, de modo de vida, nas metrópoles.

"O resultado da cada vez mais explosiva contradição é o desenvolvimento gradual daquilo que podemos chamar de uma consciência anticapitalista; o desenvolvimento de uma consciência anticapitalista e de uma estrutura mental anticapitalista, inconsciente, entre a população nas metrópoles, uma consciência ainda largamente desorganizada, espontânea, sem objetivos definidos, mas, de qualquer modo, a consciência e instintos, pulsões, "compulsões", que muito definitivamente surgem em conflito com os valores operacionais exigidos para manter o sistema capitalista. Isto é, o protesto surge em conflito com o assim chamado princípio de desempenho, que é o princípio de realidade que governa a sociedade capitalista" (MARCUSE. In: JANSEN; REITZ, 2015, p. 66). ${ }^{12}$
\end{abstract}

O protesto, para Marcuse, surge de necessidades biológicas e vitais dos indivíduos, quando não aceitam mais viver como vivem, sob condições penosas. Os indivíduos sofrem sob as condições de exploração econômica e a exclusão de direitos. Aos poucos, começam a querer mais do que as migalhas que lhes são oferecidas. Negros, mulheres, LGBTQs, imigrantes, refugiados, começaram por exigir seus direitos dentro da ordem, cujos dirigentes possuem dificuldades no reconhecimento desses grupos devido à disputa daqueles que estão à frente do Estado. Marcuse não discutiu questões religiosas que, muitas vezes, aparecem como justificativas para restringir direitos. E, atualmente, as disputas religiosas surgem como imperativos de grupos conservadores dentro do Estado e guerras religiosas em

12 “(...) This contradiction threatens to explode; not through spreading poverty and misery in the metropoles, but on the contrary, through the potential conquest of material want and misery. That is to say, the contradiction develops on a relatively high level of living, standard of living, in the metropolitan countries.

The result of the ever more explosive contradiction is the gradual development of what we may call an anti-capitalist consciousness; the development of an anti-capitalist consciousness and of an anti-capitalist mental structure, unconscious, among the population in the metropoles, a consciousness still largely unorganized, spontaneous, without definite goals, but, in any case, the consciousness and instincts, drives, "compulsions," which very definitely come into conflict with the operational values required to sustain the capitalist system. That is to say, the protest comes into conflict with the so-called performance principle, which is the reality principle governing capitalist society." 
outras regiões. Mesmo assim, Marcuse acreditava na perspectiva de protesto dos excluídos como motivo de libertação. Esse protesto demanda uma nova sensibilidade, o sentimento de solidariedade e compreensão do outro, contra a falta de empatia do processo de reificação predominante na sociedade competitiva. Por isso, ele acreditava que o movimento feminista é um movimento de radical importância. O reconhecimento de direitos - direito ao corpo, equivalência salarial e de oportunidades - vai além da esfera capitalista na medida em que muda as relações humanas e sociais dentro dessa sociedade.

A nova sensibilidade passa pela recusa daquilo que a sociedade estabelecida oferece, como a violência quotidiana, a agressividade banal exercida pelas instituições oficiais ou fomentada pela mídia. Recusa de aceitar a destruição ambiental por interesses de grupos econômicos, de comer alimentos envenenados, de destruição de povos nativos, de fomentar guerras, de aumentar o desperdício. Muitas dessas recusas estavam presentes nos anos 1960, e as novas gerações parecem estar compreendo a importância delas e desenvolvem outra sensibilidade, inclusive em relação ao consumo e ao modo de vida. Há boicotes a empresas acusadas de trabalho escravo ou que vendam produtos com imagens machistas. Algumas empresas já buscam se comportar eticamente adotando políticas mais inclusivas. Trata-se de um processo lento que ainda não sabemos os limites. Mas é um processo ainda inserido num modo de produção excludente e explorador. As revoltas são desorganizadas e surgem como resistência e enfrentamento e não como algo totalmente efetivo. Ainda são lutas por reconhecimento, reconhecimento da diversidade em meio ao encaixe unidimensional que se impõe. Uma educação para a inclusão e para a diversidade, reconhecimento do outro, pluralidade, contra uma vida sufocante, é necessária acima de tudo. Contra a propaganda oficial é necessário contrapropaganda. Para Marcuse, os limites do capitalismo são os limites da concentração de riqueza e da abundância de mercadorias em meio à miséria geral.

Em 2010, o Occupy Movement começou a denunciar, ingenuamente, a cobiça dos 1\% contra a miséria reinante dos $99 \%$ da população. Houve a partir daí vários movimentos no mundo, como a Primavera Árabe, reivindicando uma vida melhor. Porém, esses movimentos foram logo devastados por um crescimento da direita e extrema direita, um processo de contrarrevolução geral. As sementes dos anos 1960 continuam brotando, e, nesse momento de grande contenção, a resistência não pode deixá-las para trás.

Marcuse, apesar de ser realista, manteve uma perspectiva otimista. Suas últimas palavras em sua derradeira palestra colocam a perspectiva da libertação. Ele se refere a uma reorientação do modo de produção, para acabar com a miséria onde ela existir, e à reconstrução do meio ambiente devastado, com a criação de espaço e tempo para o trabalho criativo. Essa reorientação envolve decidir sobre a incessante produção de mercadorias tecnológicas e qual sua real necessidade. Isto implicaria, talvez, num rebaixamento do nível de vida da população privilegiada dos países mais avançados, mas seria um pequeno preço a pagar. Eu cito: "A abolição do desperdício, do luxo, da obsolescência planejada, de serviços desnecessários e mercadorias de todo tipo podem bem significar um padrão de vida mais baixo, 
que pode não ser um preço muito alto a se pagar pelo possível advento de uma sociedade socialista livre" (MARCUSE. In: JANSEN; REITZ, 2015, p. 69). ${ }^{13}$

\section{REFERÊNCIAS}

JANSEN, Peter-Erwin e REITZ, Charles (Orgs.). Herbert Marcuse's 1974 Paris Lectures at Vincennes University from Marcuse Archives. Global Capitalism and Radical Opposition. Introduction by Sarah Surak and afterwords by Douglas Kellner. Salisbury University. Maryland, USA, 2015.

LOWERY, Annie. "Incomes Flat in Recovery, but Not for the 1\%." The New York Times, February 16, 2013, B-1.

MARCUSE, Herbert. O homem unidimensional - Estudos da ideologia da sociedade industrial avançada. Trad. Robespierre de Oliveira, Rafael Cordeiro Silva, Deborah Antunes. São Paulo: Edipro, 2015.

MARCUSE, Herbert. Tecnologia, guerra e fascismo. Douglas Kellner (Org.). Trad. Maria Cristina Vidal Borba. São Paulo, UNESP, 1999.

REITZ, Charles. "Celebrating Herbert Marcuse's One-Dimensional Man: Deprovincialization and the Recovery of Philosophy", palestra dada na Universidade de Columbia em abril de 2014, publicada em Radical Philosophy Review, v. 19, n. 1, 2016.

REITZ, Charles e SPARTAN, Stephen. "The Political Economy of Predation and Counterrevolution", Chapter 1. In: Reitz, Charles. Crisis and Commonwealth, Lanham, MD, Lexington Books, 2015, p. 19-41.

\section{Dados do Autor}

\section{Robespierre de Oliveira}

Doutor em filosofia pela Universidade de São Paulo. Professor associado da Universidade Estadual de Maringá. Maringá/PR - Brasil. roliveira@uem.br.

Submetido em: 31-3-2017

Aceito em: 7-8-2017

\footnotetext{
13 "The abolition of waste, luxury, planned obsolescence, unnecessary services and commodities of all kind may well mean a lower standard of living, which 1. may not be a price too high to pay for the possible advent of a free socialist society."
} 